Resaerch Paper:

\title{
Cardiac Function Modeling in Patients With Acute Myocardial Infarction Based on Type D Personality Considering the Mediating Role of Health-Promoting Lifestyle
}

\author{
Yarali Dousti $^{1}$ (D), Marzieh Mohammadi Pashaki ${ }^{{ }^{*}}$ (D), Bahram Mirzaian ${ }^{1}$ (D)
}

1. Faculty of Clinical Psychology, Sari Branch, Islamic Azad University, Sari, Iran

$\begin{aligned} & \text { Use your device to scan } \\ & \text { and read the article online }\end{aligned}$
Cftation Dousti Y, Mohammadi Pashaki M, Mirzaian B. Cardiac Function Modeling in Patients With Acute Myocardial Infarction
Based on Type D Personality Considering the Mediating Role of Health-Promoting Lifestyle. Avicenna J of Neuropsychophysiology.
2018; 5(2):53-62. http://dx.doi.org/10.32598/ajnpp.5.2.53
doli http://dx.doi.org/10.32598/ajnpp.5.2.53

\section{(c) (i) (3)}

Article info:

Received: 10 Nov 2017

Accepted: 13 Feb 2018

Available Online: 01 May 2018

Keywords:

Type D personality, Lifestyle, Cardiac function, Acute myocardial infarction

\section{A B STRACT}

Background: The cardiac function of patients with acute myocardial infarction plays a vital role in disease prognosis. The risk of ischemic heart disease and death in people with type $D$ personality is 4 times more than those with lower levels of negative affect and social inhibition. In this regard lifestyle is the objective and quantifiable dimension of human personality.

Objectives: The research aimed to model the cardiac function based on type $D$ personality with the mediating role of health-promoting lifestyle in patients with acute myocardial infarction.

Materials and Methods: The present research has employed a correlational method based on structural equation modeling, especially the regression equation. The statistical population of this research included all patients with acute myocardial infarction (ST-segment elevation MI) under primary percutaneous coronary intervention referred to Mazandaran Cardiac Center in Sari City, Iran, from 2017 to 2018. A total of 220 patie nts were selected through the Muller regression equation modeling formula, considering the ratio of the sample size to the free parameter, by the purposive sampling method. They responded to the $D$ personality questionnaire and the healthpromoting lifestyle questionnaire.

Results: Type D personality variable can directly predict the cardiac function of patients with acute myocardial infarction. This variable also predicts the cardiac function of these patients through the mediation of a health-promoting lifestyle.

Conclusion: Type $D$ personality has a direct and indirect effect on the heart disease and prognosis of patients with myocardial infarction (because of the mediating role of health-promoting lifestyle), and screening for this personality type is necessary.

\section{* Corresponding Author:}

Marzieh Mohammadi Pashaki, PhD.

Address: Faculty of Clinical Psychology, Sari Branch, Islamic Azad University, Sari, Iran.

Tel: +98 (911) 33216733

E-mail: marzieh.mohammadi1351@gmail.com 


\section{Introduction}

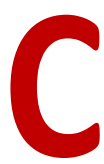

ardiovascular disease is the most common cause of death in most countries of the world, including Iran. It will be the leading cause of mortality across the globe by 2020 according to the World Health Organization

(WHO) [1, 2]. Myocardial infarction is one of the leading causes of infection, hospitalization, disability, and death in human societies and does not confine to a specific age group or gender [3, 4]. If a significant part of the myocardium suffers from ischemic injury, the pumping function of the left ventricle reduces. This disorder is the single essential predictor of mortality following ST-elevation myocardial infarction [5, 6]. Medical treatments, including thromboembolic drugs and angioplasty using balloon or spring, are used to limit myocardial infarction and prevent damage to the myocardium [7].

The known biological agents cannot fully explain the incidence of cardiovascular disease [8], but psychological and personality factors have a direct and indirect role in initiating and exacerbating cardiovascular disease [7, 9]. Personality is a set of relatively durable and unique features that may vary in response to different situations [10]. In the late 1990s and early 21 century, Denolt emphasized a new type of personality type called "Type D" by the typology of cardiovascular patients, which could predict heart disease with its characteristics [11].

The type $D$ personality is defined as the interaction of two fixed and general personality traits, consisting of negative emotions and social inhibition. In negative emotions, the individual tends to experience negative feelings at different times and situations and feels more emotional, anxious, and irritable feelings. Social inhibition refers to people's desire to avoid negative emotions in social interactions, and individuals in this feature interact with others and feel distraction, stress, and insecurity [12-14]. The risk of ischemic heart disease and death in people with type $D$ personality is 4 times more than those with lower levels of negative affect and social inhibition, and this is independent of the risk factors of traditional biomedicine [15-17].

The negative affections of type $D$ personality in patients with myocardial infarction are the predictor of disability and low quality of life among them [16]. And the low quality of life predicts mortality in cardiovascular patients [15]. However, since there was no relationship between the behavior of type $D$ personality and the risk of cardiovascular disease in all studies, this kind of personality type needs more research [18]. Although extensive research in Western countries confirms the relationship between type $D$ personality and the occurrence of cardiac problems, this study needs to be conducted in non-western countries, too [11].

Lifestyle is the objective and quantifiable dimension of human personality. Adler introduced the concept of lifestyle in the early 1900s. Lifestyle is the most important factor, based on which everyone regulates his or her life; a healthy lifestyle includes behaviors that guarantee the physical and mental health of a person $[19,20]$.

The WHO considers lifestyle as personal and identifiable patterns of behavior that result from the interaction among personal characteristics, social relationships, environmental conditions, and socioeconomic situations [21]. Health-promoting lifestyle includes practices such as nutrition, physical activity, health responsibility, stress management, interpersonal relationships, and spiritual growth [22]. An inappropriate lifestyle is one of the factors affecting the development of chronic diseases and one of the most important causes of death in Iran [23].

Unhealthy eating habits, not exercising, and smoking are common behaviors that increase the risk of developing physical and chronic illnesses, especially hypertension and cardiovascular problems, in the long run $[18,24]$. Having a healthy lifestyle can prevent many diseases [25]. Various studies show that lifestyle changes not only inhibit heart disease but also control its progress and reduce complications in patients with cardiovascular disease [26]. For example, quitting smoking after myocardial infarction reduces the relapse risk by up to $35 \%[25]$.

According to the first statement of the World Health Conference in Moscow, $60 \%$ of global mortality and $80 \%$ of deaths in developing countries are the result of unhealthy lifestyles, and figure 1 will reach $70 \%$ of global mortality by 2030 [27]. Urbinati showed that in spite of the strict adherence to drug therapy in patients with coronary heart disease and diabetes, they could not maintain their proper blood pressure and low-density lipoprotein without following a healthy lifestyle after the diagnosis [28]. Cardiovascular diseases are treatable, and the best prevention is to adopt a healthy lifestyle [29]. Shanshan Li et al. showed that a higher-quality diet in patients with post-myocardial infarction reduces mortality in all cases [30].

Several studies have examined the risk factors for cardiovascular diseases, but few studies have been conducted regarding the role of personality traits in life- 
style, as well as the relationship between cardiovascular lifestyle and cardiovascular risk factors [19, 22]. Despite the high impact of psychological risk factors in coronary artery disease itself, its prevention, and treatment, this dimension is often overlooked [20]. Many studies have been conducted on the psychological factors and coronary heart disease through correlation, causality, and effectiveness methods. However, in this research, we tried to use the new method of Structural Equation Modeling (SEM) for type D personality on the cardiac function of myocardial infarction patients with the mediating role of lifestyle. The research in this field is necessary because of the importance of lifestyle and its significant effect on preventing diseases and protecting the health of individuals. Also, the increasing number of people suffering from chronic diseases will be another reason for such studies.

\section{Materials and Methods}

This research has employed a cross-sectional method to collect the required data. The obtained data were analyzed through the descriptive and correlational methods based on SEM. In particular, we used the regression equation (integration of path analysis and factor analysis of the second level), based on covariance approaches (CBSEM) done in AMOS software. This approach estimates path coefficients and factor loadings by minimizing the difference between a sample-based covariance matrix and a model-based covariance matrix. Also, Baron and Kenny's step approach was used to investigate the correlation between variables, exogenous and mediator, and mediator and endogenous. Finally, the mediating role of exogenous and endogenous variables was examined [31].

The statistical population of this study included all patients with acute myocardial infarction (ST-segment elevation MI) referred to the Emergency Ward of Mazandaran Cardiovascular Hospital from 2017 to 2018 under primary Percutaneous Coronary Intervention (PCI).

The inclusion criteria included patients 1 . Aged 30 to 65 years old; 2 . Diagnosed with acute myocardial infarction under primary Percutaneous Coronary Intervention (PCl) [5]; 3. Wanted to participate in the research voluntarily; 4 . Could read and write to complete the study questionnaire. Individuals diagnosed with STsegment elevation MI should have the following clinical features: ST-segment elevation, high levels of cardiac enzymes, and the clinical history of angina and coronary artery stenosis above $50 \%$, confirmed by angiography.
The exclusion criteria included failure to complete the questionnaire, withdrawal from continuing research activities, developing physical, psychological, and emotional problems during the study. To determine the sample size, we used the Muller regression equation modeling formula considering the ratio of the sample size to the free parameters [32]. Regarding the number of free parameters, 220 samples were obtained according to the average in the targeted sampling method.

The implementation method initially reviewed the records of hospitalized patients in the special wards of the hospital, who were aged 30 to 65 years old with the diagnosis of acute myocardial infarction under primary $\mathrm{PCl}$. We used the D personality (DS14) and the HealthPromoting Lifestyle (HPLP II) questionnaires in this research. In the first step, the demographic information was obtained by taking the biographies of the patients and studying their records and the severity of coronary artery involvement through the angiographic report sheet considering the inclusion criteria. The questionnaires were then given to the patients, and they were asked to answer all the questions by explaining how to complete the questionnaire. Cardiac function was recorded with the Ejection Fraction index recorded in the echocardiographic artery.

\section{Study instruments}

\section{D personality Questionnaire}

Denolt designed the D Personality Questionnaire (DS14). It has 14 questions and two subscales of negative emotions and social inhibition [12]. This scale is at a desirable level in terms of reliability with as much as $81 \%$ obtaining through the test-retest method in Belgium. Based on the Cronbach alpha method, the reliability of this scale is 0.86 [33]. The validity of this scale is also at a desirable level so that the subscale of negative emotions with neuroticism has a correlation of 0.74 , which is significant at the level of 0.001 . There is a positive correlation between social inhibition and extroversion ( $r=-0.61)$ and a negative relationship between social inhibition and the level of consciousness $(r=-0.40)$. There is also a positive correlation between social inhibition and neuroticism $(r=0.50)$. These coefficients are all significant at 0.001 [12].

Zoljanahi et al. in Iran obtained the internal reliability of the negative emotion and social inhibition scale as 0.77 and 0.69 , respectively [34]. Fakhari et al. calculated the Cronbach alpha for the negative emotion and social in- 
Table 1. Questions of the questionnaire and the dimension

\begin{tabular}{|c|c|}
\hline Dimension & Related Questions \\
\hline Nutrition & $1-11$ \\
\hline Sport & $12-24$ \\
\hline Health responsibility & $25-32$ \\
\hline Stress management & $33-38$ \\
\hline Interpersonal support & $39-46$ \\
\hline Self-actualization & $47-54$ \\
\hline
\end{tabular}

hibition scale as much as 0.79 and 0.56 , respectively. The alpha value for the total reliability of DS14 was 0.83 [35].

The questionnaire was rated based on a 5-point Likert scale from $0,1,2,3$, and 4 (indicating incorrect, somewhat incorrect, I do not have any idea, somewhat correct, and correct). Higher scores (closer to 56) shows the presence of the Type $D$ personality.

\section{Health-Promoting Lifestyle Questionnaire}

Health-Promoting Lifestyle (HPLP II) questionnaire is a modified version of HPLP presented by Walker et al. It measures the health-promoting lifestyle by focusing on innovative work and individual perceptions that maintain or increase the level of well-being, self-actualization, and individual satisfaction.

This tool has 52 items and measures health-promoting behaviors in 6 dimensions. The measurable dimensions include nutrition (having a food pattern and choosing food), sports (pursuit of regular sport patterns), health accountability, stress management (identifying stress sources and stress management practices), interpersonal relationships and support (maintaining relationships with the feeling of proximity), spiritual growth, and self-actualization (having a sense of purposefulness, seeking to advance individuality and experience of self-awareness and satisfaction). Regarding the scoring, the respondent was asked to specify how much he or she performs health promotion behaviors on the 4-point Likert scale (never, sometimes, often, and normally). Generally, the health-promoting lifestyle score and behavioral dimension scores are calculated using average responses for 52 questions and each subcategory (8-9 items).

Hill-Polerecky and Walker reported the alpha value of 0.94 for the HPLP II tool and 0.79 to 0.94 for the sub- categories. The reliability of the 3-week test-retest for the whole questionnaire was 0.89 [36]. In the study of Zaidi et al.the Cronbach alpha for the entire tool was 0.82. Also, the Cronbach alpha for the subcategories, including nutrition, physical activity, health responsibility, stress management, interpersonal relationships, spiritual growth, and the whole questionnaire was 0.81, 0.79, $0.86,0.91,0.75,0.64$, and 0.82 , respectively [36]. SPSS 18 and AMOS software were used to analyze the data. Table 1 presents the questions of the questionnaire for each dimension.

\section{Results}

Initially, By reviewing statistical defaults, Outliers data were identified by examining statistical using box, tensile and skewness tests, Kolmogorov-Smirnov tests then were eliminated by Mahalanobis test and It was finalized with 201 samples, and the final data were extracted with 201 samples. Also, after evaluating the data normalized distribution, the measured model of two variables of research was assessed and confirmed. Besides, the average extraction variances show that all subscales of character type $D$ variables and health-promoting lifestyle are greater than 0.5 . The measured standards in the model, representing convergent validity and compound value (construct validity), indicate that the values obtained from the components are greater than 0.07 i.e., the measured standards. Therefore, the subject of average extraction variances and construct reliability for questionnaires are verified.

The results presented in Table 2 show a significant correlation between type $D$ personality, lifestyle, and health promotion with heart function $(P=0.01)$. According to Table 3 , the value of RMSEA is 0.444 , which indicates the model is acceptable. Also, the Chi-square to the degree of freedom is 2.795 . The GFI, CFI, and NFI 
Table 2. Mean $\pm S D$ and correlation of type $D$ personality, lifestyle, and promotion of health with heart function

\begin{tabular}{cccccccccc}
\hline Variable & Mean \pm SD & $\mathbf{1}$ & $\mathbf{2}$ & $\mathbf{3}$ & $\mathbf{4}$ & $\mathbf{5}$ & $\mathbf{6}$ & $\mathbf{7}$ & $\mathbf{8}$ \\
\hline Nutrition & $22.91 \pm 7.24$ & 1 & & & & & & & \\
\hline Exercise & $20.89 \pm 7.64$ & $39^{*}$ & 1 & & & & & \\
\hline Responsibility of health & $20.42 \pm 7.25$ & $24^{*}$ & $34^{*}$ & 1 & & & & \\
\hline Stress management & $13.27 \pm 3.65$ & $48^{*}$ & $51^{*}$ & 44 & 1 & & & \\
\hline Interpersonal support & $17.27 \pm 5.75$ & $46^{*}$ & $57^{*}$ & $52^{*}$ & $38^{*}$ & 1 & & \\
\hline Self-actualization & $20.70 \pm 6.45$ & $68^{*}$ & $46^{*}$ & $46^{*}$ & $62^{*}$ & $58^{*}$ & $1^{*}$ & & \\
\hline $\begin{array}{c}\text { Type D personality } \\
\text { Ejection fraction heart } \\
\text { function }\end{array}$ & $24.67 \pm 4.91$ & $55^{*}$ & $48^{*}$ & $30^{*}$ & $25^{*}$ & $21^{*}$ & 20 & 1 \\
\hline
\end{tabular}

$* P<0.05$

AJNPP

Table 3. Fit indicators obtained from data analysis and variables after two correction steps

\begin{tabular}{|c|c|c|c|c|}
\hline Test & Description & Acceptable Values & $\begin{array}{l}\text { The amount Obtained } \\
\text { Before the Correction }\end{array}$ & $\begin{array}{l}\text { The Amount Obtained } \\
\text { After the Correction }\end{array}$ \\
\hline$\chi^{2} / \mathrm{df}$ & Relative normed Chi-square & $>3$ & 3.20 & 2.795 \\
\hline$x^{2}$ & Chi-square & & 220.467 & 198.457 \\
\hline df & Degrees of freedom & & 73 & 71 \\
\hline RMSEA & $\begin{array}{l}\text { Root mean square error of ap- } \\
\text { proximation }\end{array}$ & $>0.1$ & .052 & 0.044 \\
\hline GFI & goodness of fit index & $<0.9$ & 0.918 & 0.938 \\
\hline $\mathrm{NFI}$ & Normed fit index & $<0.9$ & 0.904 & 0.931 \\
\hline CFI & Comparison fitness index & $<0.9$ & 0.899 & 0.914 \\
\hline
\end{tabular}

AJNPP

indices approximately equal to 0.9 and show that the model is appropriate for measuring variables. According to Table 4, type D personality and health-promoting lifestyle have a direct effect on heart function.

Based on the Table 4, From the indirect path considered according to standardized values $(\beta)$, not standardized $(b)$ and $\left(R^{2}\right)$ obtained, the path of type $D$ personality with medi- ating the life-style of promoting health on heart function has significant effects with respect to the obtained values and is confirmed by the Bootstrap estimation method. the path of type $D$ personality with mediating the life-style of promoting health on heart function has significant effects with respect to the obtained values and is confirmed by the Bootstrap estimation method Table 5 .

Table 4. The direct estimation of the model with the maximum-likelihood estimation

\begin{tabular}{ccccc}
\hline Variable & B & B & $\mathbf{R}^{\mathbf{2}}$ & Sig. \\
\hline Personality type D on heart function & 0.21 & 0.19 & 0.039 & 0.034 \\
Health-promoting lifestyle on heart function & -0.54 & 0.34 & 0.183 & 0.01 \\
\hline
\end{tabular}

AJNPP

Table 5. Indirect estimation of the model using the Bootstrap method

\begin{tabular}{ccccc}
\hline Variable & B & Lower Boundary & Upper Boundary & Sig. \\
\hline Type D personality on heart function by mediating lifestyle & 0.318 & 0.296 & 0.423 & 0.001 \\
\hline & & & & AJNPP
\end{tabular}




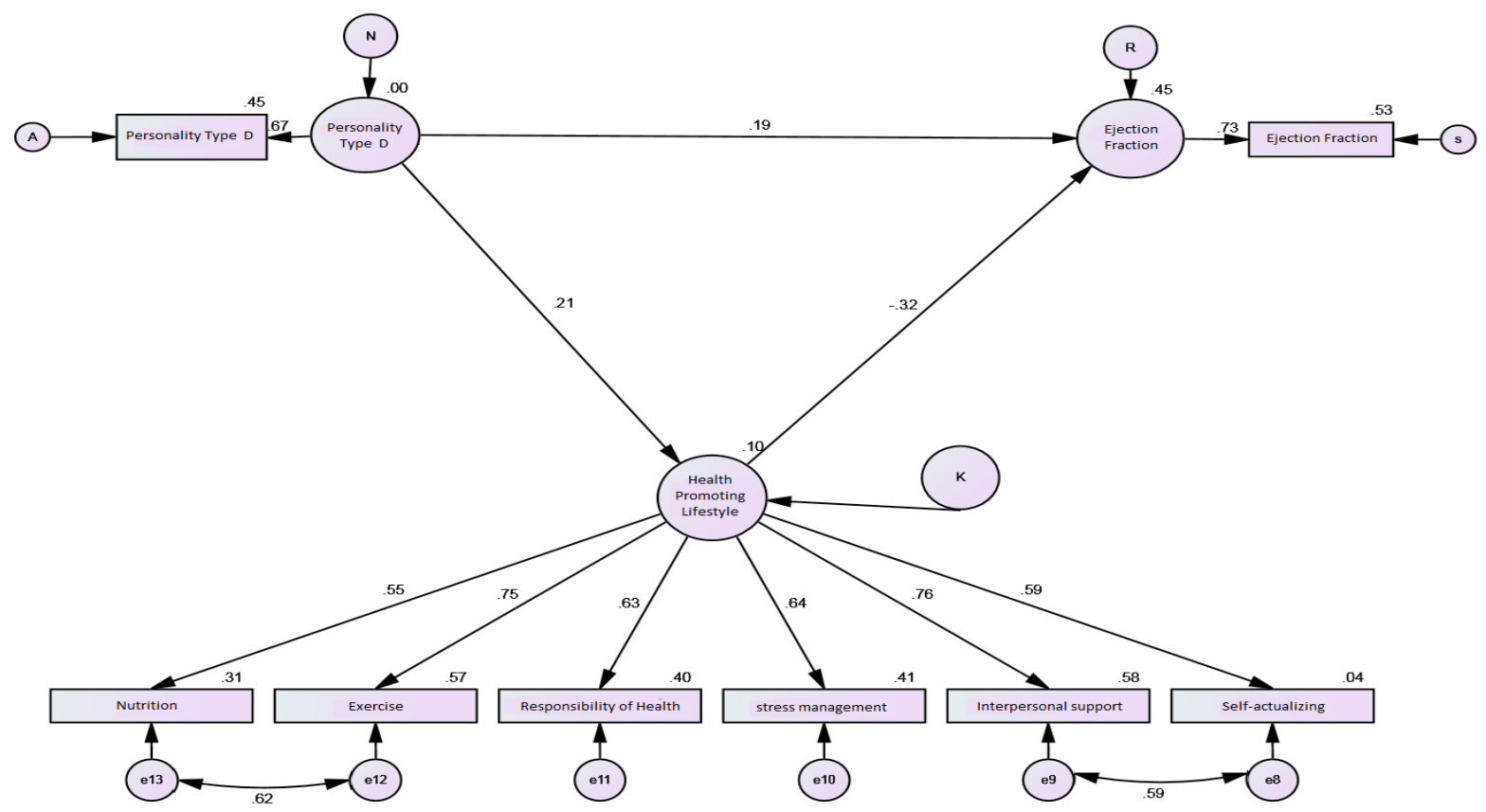

AJNPP

Figure 1. The final model of predicting the heart function in the indirect pathway by the type $D$ character variable with mediating lifestyle

It is worth noting that in the final model for creating latent variables, it is necessary to have multiple markers of each of the variables. We usually use the subscales of the measurements as separate indicators of the construct, but in some cases, there is no specific design of a particular structure. In this case, the item packets described by Russell et al. are used. In this study, this method was also used to analyze the type $D$ personality and the heart function according to the single variables to improve the overall variance of the model based on Russell et al. method in the hidden variable [37].

\section{Discussion}

The present research aimed to model the structural relationships of type $D$ personality with the cardiac function of patients with acute myocardial infarction with the mediating role of a health-promoting lifestyle. According to the final model of the research, the Type $D$ personality variable can predict cardiac function in patients with acute myocardial infarction. Investigating the predictive role of type D personality and health-promoting lifestyle in predicting cardiac function in patients with acute myocardial infarction also showed a correlation coefficient of 0.039 and 0.18 in patients with acute myocardial infarction. In addition, the indirect effect of type $D$ personality variable on the cardiac function of patients with acute myocardial infarction with mediating the health-promoting lifestyle explained variance $\left(R^{2}\right)$ as much as 0.37 , indicating an indirect effect on the cardiac function of patients with acute myocardial infarction. These results are consistent with the studies of Urbinati et al.Shanshan Li et al.Hemati Pak Maslak et al.and Mazloumi et al. They reported that a health-promoting lifestyle affects cardiovascular patients, especially those with myocardial infarction. This lifestyle helps patients to control their blood pressure, cholesterol, diabetes, cardiac function better, and to reduce the death rate [26-28, 30]. In addition, this research is in line with the research done by Mohseni Pouya et al.Saber Moghaddam Ranjbar et al.Besharat et al.Aminpour et al.and Etemad on the effect of lifestyle in the development of coronary heart disease $[20,22,23,38,39]$. The results were also consistent with the Sedaghat et al.Stein et al.and Mirzaie et al. study results which reported that following a promoting lifestyle, especially in cardiac patients, is not only being aware of a healthy lifestyle but is also being influenced by psychological factors such as personality type and motivation $[19,24,29]$. These findings emphasize the importance of psychological issues in the health area of cardiac patients.

Personality can be considered the distinct patterns of thinking, emotion, and behavior that interact with each individual's physical and social environment [40]. Not many aspects of human action can reflect its personality [41]. Whatever human beings have gained or will bring, including their general health status, is influenced by their personality and those with which they are interacting [10]. Personality types are a model, by which the real person can be evaluated. Each type has certain 
reserves of attitudes and skills to overcome problems and environmental tasks [42]. The theoretical basis for the personality type $D$ was the study of heart patients in Belgium, in which the role of personality traits was examined in the outcomes of heart disease [12].

Type D personality affects the biological causes (e.g. blood pressure, blood lipids, and tobacco use) of coronary heart disease [22, 23, 29]. In the present research, the mean scores of stress control and interpersonal relationships and support were 13.27 and 17.27, respectively, which gained lower scores compared with the mean scores of the other dimensions of health-promoting lifestyle. The type $D$ personality is defined as the interaction of two fixed and general personality traits, consisting of negative emotions and social inhibition. Regarding the negative emotions, the individual tends to experience negative emotions in different times and situations, and regarding social inhibition, people tend to avoid negative emotions in social interactions. In this feature, individuals feel distraction, stress, and insecurity while interacting with others [12-14].

People with negative emotions and social inhibition often suffer from chronic stress, low social support, and a low level of well-being [11]. The results of this study can support the notion that personality is an important and significant component in explaining the lifestyle as an internal and interpersonal factor. Establishing social relationships can promote physical mobility, and this activity leads to physical and mental health [19]. According to the social-cognitive theory of Bandura, most of the information is obtained through mutual interaction with others [43]. Therefore, having social relationships provides a learning and modeling opportunity for other people's positive behaviors on issues such as stress management, proper nutrition, and quality. Moreover, having social relationships will lead to social support, spiritual growth, and self-actualization. Studies have shown that heart patients with social support are more likely to recover and have lower death rates [7].

Type D personality with social inhibition can interfere with interpersonal and social relationships, which is one of the essential components of lifestyle. In most of the mentioned studies, analytical-descriptive or interventional methods have been used; moreover, the effect of lifestyle in the development of cardiovascular diseases or the impact of education on lifestyle and achievement of therapeutic goals in cardiovascular patients were examined. However, the SEM has been used in this research, which investigated the effect of personality type $D$ on the cardiac function that determines prognosis in patients with myocardial infarction through the mediating role of lifestyle. Therefore, this study is different from other studies in terms of methodology.

The results of this research will be proposed to general health specialties, health psychologists, cardiologists, and intensive care unit nurses. Interventions can be considered for improving cardiac function and better prognosis in acute myocardial infarction by identifying factors that affect coronary heart disease and cardiac function. Lifestyle is regarded as the quantitative dimension of personality, which is an essential factor in the development of chronic diseases, including coronary heart disease. Therefore, the timely identification of coronary heart disease in patients with type $D$ personality and psychological interventions can influence their lifestyle.

As a result, the clinicians can achieve therapeutic goals, including the proper cardiac function in patients with myocardial infarction. The research method can be mentioned as one of the limitations because of using selfreport tools, which were sometimes lengthy and tedious and out of the patient's physical condition. Therefore, it is suggested to conduct the present study prospectively and after the recovery of the disease. According to the studies conducted in the field of positive psychology and health psychology, we recommend that the effects of other variables such as mindfulness, self-efficacy, optimism, and coping styles on the cardiac function of myocardial infarction patients should be investigated.

\section{Ethical Considerations}

Compliance with ethical guidelines

All the participants were given information about thegoal of the study. They were aware that taking part in this study was voluntary and had the right to refuse participation or leave the study whenever they wish. The Ethical Code is IR.IAU.SARI.REC.1397.027.

Funding

This article has been extracted from the PhD. dissertation of the first author, Yarali Dousti in Faculty of Clinical Psychology, Sari Branch, Islamic Azad University, Sari.

Authors' contributions

All authors contributed to preparing this article.

\section{Conflict of interest}

The authors declared no conflict of interest. 


\section{References}

[1] Mosa Farkhani E, Baneshi MR, zolala F. [Survival rate and its related factors in patients with acute myocardial infarction. Medical Journal of Mashhad University of Medical Sciences (Persian)]. 2014; 57(4):636-46.

[2] Rahimzadeh M, Kavehie B. Short-term survival rates after myocardial infractions in iran: Meta-analysis and systematic review. Journal of Arak University of Medical Sciences. 2017; 20(3):57-67.

[3] Ebrahimi K, Salarilak S, Khadem Vatan K. Determine the burden of myocardial infarction. Tehran University Medical Journal. 2017; 75(3):208-18.

[4] Samawat T, Hojatzadeh A, Shams M. The ways of prevention and control of cardiovascular diseases (Specialized Government Employees). Tehran: Javan Publication; 2012.

[5] Braunwald E. Heart disease: A textbook of cardiovascular medicine. [M. Nemati, Persian trans.]. $9^{\text {th }}$ edition. Tehran: Parsian Danesh Publication; 2012.

[6] Lango F, Gamson K, Loscalso H. Harrison's internal medicine principles: Heart and disease. [H. Goodarzinaghad, M. Khodaee, S. Arazaghi, Manouchehr Guaroni, Persian trans.]. Tehran: Arjmand Publication; 2010.

[7] Sarafino EP. Health psychology: Biosychological introduction. [SA. Ahmadi Abhari, H. Eftekhar Ardebili, A. Jazayeri, F. Shafiei, P. Ghavamian, GR. Garmaroudi, Persian trans.]. Tehran: Roshd Publication; 2015.

[8] Khadem Vatani K, AgaKhani N, Asma Hosseini GR, Hazrati A, Alinejad V, Nazari H. Relationship between spiritual health and anxiety and depression in patients with myocardial infarction admitted to Seyyed-Alshohada Hospital of Urmia University of Medical Sciences. Urmia Medical Journal. 2014; 25:1092-01.

[9] Kramer GP, Bernestine DA, Phares V. Introduction to clinical psychology. $8^{\text {th }}$ edition. [M. Firozbakht Persian trans.]. Tehran: Arasbaran Publication; 2016.

[10] Schultz DP, Schultz SA. Theories of Personality. Yahya Sayyed Mohammadi Translation. $8^{\text {th }}$ ed. Tehran: Virayesh; 2015.

[11] Adelnasab $L$. The role of personality type $D$ and burnout in the prediction of non-occurrence of heart disease. [MA. thesis]. Tabriz : University of Tabriz; 2011

[12] Denollet J. Personality and coronary heart disease: The type-D scale-16 (DS16). Annals of Behavioral Medicine. 1998; 20(3):209-15. [DOI:10.1007/BF02884962] [PMID]

[13] Denollet J. DS14: Standard assessment of negative affectivity, social inhibition, and type D personality. Psychosomatic Medicine. 2005 67(1):89-97. [DOI:10.1097/01.psy.0000149256.81953.49] [PMID]

[14] Pedersen SS, Denollet J. Type D personality, cardiac events, and impaired quality of life: A review. European Journal of Cardiovascular Prevention and Rehabilitation. 2003; 10(4):241-8. [DOI:10.1097/00149831-200308000-00005] [PMID]

[15] Ogińska-Bulik N. Type D personality and quality of life in subjects after myocardial infarction. Kardiologia Polska. 2014; 72(7):624-30. [DOI:10.5603/KP.a2014.0066] [PMID]

[16] Williams L, O'Connor RC, Grubb NR, O'Carroll RE. Type D personality and three-month psychosocial outcomes among patients postmyocardial infarction. Journal of Psychosomatic Research. 2012 72(6):422-6. [DOI:10.1016/j.jpsychores.2012.02.007] [PMID]
[17] Grande G, Romppel M, Barth J. Association between type D personality and prognosis in patients with cardiovascular diseases: A systematic review and meta-analysis. Annals of Behavioral Medicine. 2012; 43(3):299-310. [DOI:10.1007/s12160-011-9339-0] [PMID]

[18] Barlow DH, Durand VM. Abnormal psychology: An integrative approach. 8th edition. [M. Firozbakht Persian trans.]. Tehran: Resa Publication; 2015.

[19] Mirzaei GR, Fathi Ashtiani A, Ahmadi Kh, Mehrabi HA, Masoud Lavasan $\mathrm{GH}$, Azad-Fallah P. [The prediction of lifestyle according to personality traits (Persian)]. Journal of Behavioral Sciences. 2014; 8(2):177-84.

[20] Besharat MA, Hosseini A, Bahrami Ehsan H, Jahed HA, Nikpajouh A [Islamic lifestyle intervention model and cardiovascular health (Persian)]. Culture in the Islamic University. 2016; 5(4):467-92

[21] Babaei S, Boroumand S. Relationship between lifestyle and cardiac self efficacy among people with heart failure. Journal of Cardiovascular Nursing. 2017; 5(4):36-44.

[22] Mohseni Pouya H, Hajimiri K, Esmaeili Shahmirzadi S, Golshani S, Hashemi Amrei SH, Seifi Makrani A. Relationship between health promoting behaviors and severity of coronary artery stenosis in angiography department in Mazandaran heart center. Journal of Mazandaran University of Medical Sciences. 2015; 25(130):19-29.

[23] Saber Moghadam Ranjbar M, Rajabzade R, Nasiry Zarin Ghabaee D. Relationship of lifestyle and hypertension in administrative employees in Bojnurd rural areas. Journal of North Khorasan University of Medical Sciences. 2014; 5(4):785-91. [DOI:10.29252/jnkums.5.4.785]

[24] Sedaghat Z, Zibaeinejad MJ, Fararouei M. Adherence to Healthy Lifestyle among Hypertensive Patients and Its Association with Anthropometric Measures. Iranian Journal of Health Education and Health Promotion. $2015 ; 3(3): 232-41$

[25] Faraji N, Pashaeypoor S, Negarandeh R. The effect of pre-discharge education and telephone follow-up on illness perception and lifestyle in patients with myocardial infarction. Avicenna Journal of Nursing and Midfery Care. 2015; 23(3):82-91

[26] Molazem Z, Rezaei S, Mohebbi Z, Ostovan M-A, Keshavarzi S. Effect of continuous care model on lifestyle of patients with myocardial infarction. ARYA Atheroscler. 2013; 9(3):186-91.

[27] Hemmati Pakmaslak M, Merghati Z, Didarloo A. [The effect of BASNEFbased educational intervention on the lifestyle of patients with heart failure (Persian)]. Payesh. 2017; 16(4):501-510.

[28] Urbinati S, Olivari Z, Gonzini L, Savonitto S, Farina R, Del Pinto M, et al. Secondary prevention after acute myocardial infarction: Drug adherence, treatment goals, and predictors of health lifestyle habits. The BLITZ-4 Registry. European Journal of Preventive Cardiology. 2015 22(12):1548-56. [DOI:10.1177/2047487314561876] [PMID]

[29] Astin F, Horrocks J, Closs SJ. Managing lifestyle change to reduce coronary risk: A synthesis of qualitative research on peoples' experiences. BMC Cardiovascular Disorders. 2014; 14:96. [DOI:10.1186/1471-2261 14-96] [PMID] [PMCID]

[30] Li S, Chiuve SE, Flint A, Pai JK, Forman JP, Hu FB, et al. Better diet quality and decreased mortality among myocardial infarction survivors. JAMA Internal Medicine. 2013; 173(19):1808-18. [DOI:10.1001/jamainternmed.2013.9768] [PMID] [PMCID]

[31] Baron RM, Kenny DA. The moderator-mediator variable distinction in social psychological research: Conceptual, strategic, and statistical considerations. Journal of Personality and Social Psychology. 1986; 51(6):1173-82. [DOI:10.1037//0022-3514.51.6.1173] [PMID] 
[32] Mueller RO. Basic principles of structural equation modeling: An introduction to LISREL and EQS, NY: Springer; 1996.

[33] Ahmadpour AR, Ahadi H, Mazaheri MM, Nafisi GH. Construction and scale validation for evaluating type $D$ personality and a study of its relationship to the coronary heart disease. Knowledge and Research in Applied Psychology. 2007; 9(32):37-60.

[34] Zoljenahi A, Agilar Vafaiy M. [The prevalence of type D personality in the community student and the assessment of the personality biologicbehavioral foundations in being susceptible to coronary heart disease (Persian)]. Paper presented at: Second Seminar of Students' Mental Health. 12-13 March 2004; Tehran, Iran.

[35] Fakhari A, Norouzi S, Pezeshki MZ. Reliability and validity of type D personality questionnaires (ds14 Persian version) in coronary artery patients. Medical journal of Tabriz University of Medical Sciences and Health Services. 2014; 36(4):78-85.

[36] Mohammadi Zeidi I, Pakpour Hajiagha A, Mohammadi Zeidi B. Reliability and validity of persian version of the health-promoting lifestyle profile. Journal of Mazandaran University of Medical Sciences. 2012; 21(1):102-13

[37] 37 Russell DW, Kahn JH, Spoth R, Altmaier EM. Analyzing data from experimental studies: A latent variable structural equation modeling approach. Journal of Counseling Psychology. 1998; 45(1):18-29. [DOI:10.1037/0022-0167.45.1.18]

[38] Aminpour S, Shahamfar M, Shahamfar J. Effects of lifestyle modification program in reduction of risk factors in patients with coronary heart disease. European Journal of Experimental Biology. 2014; 4(1):353-7.

[39] Etemad Z, Ismailnasab A. [Relationship between physical activity level and some coronary risk factors (CHD) in students (Persian)]. Scientific Journal of Kurdistan University of Medical Sciences. 2012; 17(1):25-35.

[40] Atkinson RA, Atkinson RC, Smith EE, Bem DJ, Hoeksema SN. Introduction to psychology. 13th edition. [MN. Barahani, et al. Persian trans.] Tehran: Roshd Publication; 2011.

[41] Fathi Ashtiani A. [Psychological tests of personality detection and mental health (Persian)]. Tehran: Be'sat Publication; 2017.

[42] Nadri S, Banitalebi Dehkordi B, Ghazanfari A. The effect of personality types A, B, C and D auditors on the content of the audit report. Journal of Accounting Knowledge and Management Auditing. 2017; 5(20):71-86.

[43] Olson MH, Hergenhan BR. Learning theories. $8^{\text {th }}$ edition. [AA. Akbar Seif Persian trans.]. Tehran: Douran Publication. 2012. 
This Page Intentionally Left Blank 